\title{
Investigation of the employees' payment system in an educational institution - A case study
}

\author{
Mojtaba Tabari $^{\mathbf{a}^{*}}$, Yousef Gholipour-Kanani ${ }^{\mathrm{a}}$, Masoumeh Seifi-Divkolaii ${ }^{\mathrm{b}}$
}

${ }^{a}$ Faculty of Management, Qaemshahr Branch, Islamic Azad University, Qaemshahr, Iran

${ }^{b}$ Member of Young Researchers Club, Qaemshahr Branch, Islamic Azad University, Qaemshahr, Iran

\begin{tabular}{|c|c|}
\hline A R T I C L E I N F O & AB S T RACT \\
\hline $\begin{array}{l}\text { Article history: } \\
\text { Received October } 1,2011 \\
\text { Received in Revised form } \\
\text { November, } 14,2011 \\
\text { Accepted } 28 \text { January } 2012 \\
\text { Available online } \\
3 \text { February } 2012 \\
\text { Keywords: } \\
\text { Payment system } \\
\text { Educational institution } \\
\text { Statistical analysis } \\
\text { Motivation } \\
\text { Employee performance }\end{array}$ & $\begin{array}{l}\text { Nowadays, wage and salary system form the most important issues in any society, and its } \\
\text { phenomenon takes dimensions with an expansion of a public organization and NGOs. } \\
\text { Organizations provide employees satisfaction through different pay programs, which force } \\
\text { them to work down more with higher quality. In this paper, we consider a survey of the } \\
\text { payment system in an Iranian university as a case study. The population of this study consists of } \\
\text { the existing documents, observations, working managers, supervisors and experts. This study is } \\
\text { carried out from the desired community based on the data collected for a period of } 18 \text { months } \\
\text { and the sample size is about } 97 \text { people. We use descriptive statistics to analyze the descriptive } \\
\text { data. We also use the one-sample Kolmogorove-Smirnov test, t-test and Friedman test for the } \\
\text { questions. The results of the existing payment system show that there is no any good condition } \\
\text { and the employee's attitude towards this system are negative based on the collected data. } \\
\text { Finally, some suggestions are recommended to improve the existing situation. }\end{array}$ \\
\hline
\end{tabular}

(C) 2012 Growing Science Ltd. All rights reserved.

\section{Introduction}

A payment system is one of the most important issues in today's societies. Payment is a phenomenon with extensive dimensions found with the development of governmental and non-governmental organizations. Traditional payment systems are not based on individual and organizational performances. Therefore, despite the increase in expenses and salaries, these kinds of motivations do not influence productivity in organizations. They may also lead to decrease the activity and act as anti-motivational factor (Cardon, 2004).

By studying from the results of different surveys about the importance of material incentives and nonmaterial motivations, it can be concluded that employees pay attention to salary and benefits in firstdegree. The reason is that the amount of their wage and salary is not adequate to meet their necessary requirements. If employees of an organization express worry towards psychological factors, it is explained that their salaries and benefits are enough and satisfactory. Therefore, when employees do

\footnotetext{
* Corresponding author. Tel: +989111514462

E-mail address: mo_tabari@yahoo.com (M. Tabari) 
not express their satisfaction either from the adequacy of their wage and salary for providing their essential needs or their unfair rules of division, human resource management will encounter an inefficiency problem and a decrease of human resources. In other hand, the lack of logic values in the payment wage and salary system creates different kinds of harmful and destructive competitions in organization so that a psychological environment of jobs becomes unsafe. This subject is a natural consequence of a payment-based age, academic background against qualification, competence and importance of duty and responsibility (Rayton, 2003; Dohmen, 2004; Piekkola, 2005).

Evidence and experiences show that the inappropriate design, weak performance of encouragement and reward system can be harmful more than its usefulness. There is also some evidences, which indicate whenever the payment system links to the ideal performance, it is effective in increasing the motivation level, attraction and maintain or skillful competent people. Thus, wage and salary systems should grow in the organization in to ensure whatever it is essential in the optimum performance. Such a system plays a basic role in motivation of employees; as a result, the goals of organization are achieved (Rau, 2006; Deci, 1972; Harwitz, 2003). However, in several organizations, the governed wage and salary system cannot provide employees' job satisfaction and goals of organizations, because it does not contain any certain direction (Koh, 2000). Therefore, necessity of systematic compilation can provide possibility of a wage salary payment based on the employees' performance and it can also provide the necessary field to prepare the improvement performance of creative human resources (Heywood, 2006).

\section{Problem explanation}

One of the most important distresses that organizations have encountered with is to make a condition that payment is going to increase the employees' motivation. They follow a question on how to design an appropriate payment system that not only maintains employees, but also increases their motivation, directly. Despite this problem, not only most represented payment programs are not useful towards making motivation in employees, but also they cannot prevent employee dissatisfaction. Paying to employees without considering their performance in an organization imposes high expenses on the organization. Consequences of this inefficient payment system include weak performance, absence of workplace, dissatisfaction, leaving job, etc. Indeed, the reason of many strikes, shirking, lack of motivation and job dissatisfaction, leaving job and decreasing in productivity of human resources is due to inequality in payment and unjust ways of salary and benefits (Schultz, 2003).

The payment system should include motivation aspects and should be designed for the systemic payment to encourage employees to have an effective performance and be incentive for hard working for applying all of their potential abilities. In assessing the effectiveness of the payment system, it should consider its ability to attract skillful and competent employees. It can encourage employees for doing right duties, maintain skillful and competent employees and finally can lead to share strategic goals and control workforce expenses.

In this paper, we study the employees' payment system in Islamic Azad University - Ghaemshar branch. In our individual-centered observation, we record factors, such as displacement of human resources, dissatisfaction, etc. In addition, employees in different official units of the university have some considerations in many cases about principles and way of payment that they put forward. It seems that some of these problems and difficulties result from inefficiency of the wage and salary system. By considering the action domain of this university and its high value in cultural and educational politics in the north part of Iran, making an effective condition seems to be necessary to increase the quality and quantity improvement of the university staffs. Since this organization has 230 official employees in different domains, it is obvious that job satisfaction and motivation of specialist human resources in the university as the most original assets play undeniable role in increasing productivity and an impact index of this university in cultural and scientific development of the north 
part of Iran. According to stated issues, these questions have a sudden insight "what is the status of the payment system in the university? and does the present system have necessary desirability?"

\subsection{Research objectives}

The overall goal of this study is to survey the employee's payment system situation in Qaemshahr Branch at Islamic Azad University. In addition, we provide a review of the payment system based on variability, such as manner of payment, payment system base, equality in payment and the ability of running the payment system.

\subsection{Research questions}

The main questions of this research are as follows,

1. What is the way of payment in the wage and salary system in the considered university?

2. What is the base of payment in the existing payment system?

3. What is the payment index of the existing payment system?

4. What is the equality of payment in the existing payment system of the university?

5. What is the running ability of the existing payment system in the university?

\section{Analytical framework and research background}

Payment is an important property of jobs, which considerably affects job attractiveness and makes a decision about selection of that job. Designing different payment systems follows different goals. The main goal of a payment system can be considered as employee retention by encouraging them to do their duties (Harwitz, 2003; Rau, 2006). In fact, this system is designed for different reasons and the primary goals are fair representation of wage and salary, balance in payments, benefits and reward for all employees in a competitive market such that it shows a successful organization by having effective forces (Heywood, 2006; Leetel, 2000; Brian, 2001; Issac, 2001; Piekkola, 2005).

Since opportunity for individuals' needs is the bases for participating individuals in organization, payment system is the most vital factor in assigning relationships of any people with organization. Thus, the purpose of any organization is to pay attention to the payment system to attract people for representing services to the organization, and to elicit motivation and their commitment towards the access the goals of organization. The primary assumption of payment system is that people are able to meet their personal needs. This principle is accomplished when an organization is aware of necessities and motivations existing among employees. If this work is accomplished and necessary acts are performed for granting their needs, employees will be remained in the organization and they will have a close cooperation with organization (Mishraa, 2000; Jensen, 1990)

Research shows that the kind and level of payments an organization pays to the employees detremine who will continue his/her job. Organizations, which pay the most payments, attract more people and can keep them for long run (Deci, 1972; Dohmen, 2004; Brian, 2010). The inappropriate design and weak performance of a salary system, wage or benefits can lose the benefits. However, whenever a payment system links to the desired performance, it can be also effective in increasing motivation level, attracting and maintaining skillful people (Schultz, 2003; Koh, 2000). Designers of the wage and salary system help the organization discover and maintain the efficient human resources. Without a suitable payment system, the existing employees probably leave the organization and their displacement is not feasible, easily. The negative results of an inefficient payment system leading to dissatisfaction in an organization include: 1) psychological resignation, 2) absence from the job, 3) leave the job, 4) job dissatisfactory, 5) strikes, 6) complaints, 7) searching for another job with more income, and 8) less attraction in present job (Schultz, 2003; Eriksson, 2000). 
Survey shows that the payment system can affect on individual and organizational behavior in important situations. The primary goals of a payment system are to attract and to preserve employees, to encourage effective performance, to promote proficiency and to flower and develop knowledge and awareness, and finally to create group culture (Miceli, 2000; Singer, 2008; Eriksson, 2000). Furthermore, strategies of the wage and salary system should be able to make a desired culture in an organization. They are able to back up the values of the organization, provide clear relationships between performance and payment, answer employees' requirements, preserve skillful employees, and provide awareness among the employees towards the types of behavior to receive reward. Tendency towards the permanent and outstanding performance, and it finally creates a link among the system's components or procedures of payment in one way and fundamental strategies of organization in another way (Parent, 2004; Leetel, 2000; Harwitz, 2003; Dohmen, 2004; Schultz, 2003; Issac, 2001; Piekkola, 2005).

Burke et al. (2005) carried out a professional practice, which optimizes the fixed and variable compensation costs for the employees' productivity. Findings show that there is a relationship between stable and variable payments and employees' productivity in the company, level of performance, risk of market, expense of asset and annual currency flow. Final selection from a combination of the compensation service system of stable and variable services should be parallel with the values and managerial goals for increasing the company productivity. Therefore, assessment of shareholders is performed and the result of this optimum combination increases the employees' productivity and motivation. Rayton (2003) stated whether the structure of wage increases the performance of company. The results of this paper show that high performance of companies has close relationship with payment and performance.

\section{Research methodology}

The method of this study is based on the descriptive survey taken from all managers, heads, supervises and experts with the five-years experience at Islamic Azad university. There are about 124 different jobs in the organization chart, in which the people who are actually appointed in the mentioned possibilities are 130. Therefore, the population size $(N)$ is considered 130 in this study. The sample size should be selected from this population, in which these people are considered for the questionnaire of the study. We compute the sample size that is equal to 97, in which the people are selected with the simple random method from the statistic population of the study. The required data are collected from the questionnaire with regard to the research literature and the existing books, documents and evidence as the collecting tools of data.

In this questionnaire, five options for answering the questions were selected according to the Likert Scale consisting of the very low rank, low rank, medium rank, high and very high rank. However, the questions $21,27,32,36,37,38$ and 39 are set in the reverse order, because of the nature of questions. The questionnaire is composed of 40 questions, which are regulated for surveying the various criteria of the payment system. The questions $2,6,7,8,12,16,22,28,30,33,34$ and 35 are related to the process of the payment. The questions $3,4,15,31,32,37,39$ are related to criteria based on payment, and the questions $9,10,11,17,18,23$ are related to be the data. The questions 1, 13, 14, 27, 36, 38 and 40 are related to criteria of equality, and finally the questions 5, 19, 20, 21, 24, 25, 26, 29 and 33 are related to the criteria of running the ability of the payment system. In this study, the values 1 and 2 represent the weakness in the system and the undesirable situation. Finally, the value 3 shows the average situation and the values 4 and 5 present the desirable (or optimal) situation. In the case that the calculated average from the findings is more than 3, the situation will be optimal. We choose these criteria because of their relationships with the staff. By considering the matter that each of these criteria can be affected by various factors, we just use from the effective factors included in this study and excluded the other effective factors, and the variability such as the organization culture, organization formation and quality of work assumed immobile. In this study, for increasing the content validity of the questionnaire, the following tools are used. 
- The survey and study of questionnaires and questions related to wage and salary,

- The study of essays and several books concerning the salary and wage subject, and related models and other relating issues,

- Use and guidance of the supervisor and professor, in which at first the questionnaire with 37 questions are designed that after final revision the number of questions became 40 that 34 of them are main questions and 4 questions are designed as controlling questions.

In addition, for the final calculation, 20 questionnaires are distributed among people after collecting with SPSS software and the total reliability via the coefficient Alpha test is calculated, in which the questionnaire amount of total Alpha is $82 \%$. This amount is more than the acceptable value $(\alpha>0.7)$ showing that the used questionnaires has high reliability and validity.

\section{Result and discussion}

To analyze and to study the collected data, we use the following approaches, namely One-Sample Kolmogorove-Smirnov Test for normality of the test, $t$-test for surveying the amount of acceptability of each variability and surveying to the first question and finally Friedman Test for ranking each variability of research. In this section, the survey of data for decision making on using from parametric and non-parametric tests for this paper the survey of being the normal data the following hypothesis are used. As shown in Table 1, the meaningful amount for five variability (i.e., payment method of wage and salary, the base of payment, payment index, equality of payment and running ability) become more than 0.05 . Thus, $H_{0}$ is accepted and all of the five variability have a normal distribution.

$$
\begin{array}{ll}
H_{0}: \text { Data have a normal distribution. } & \text { sig. } \geq 0.05 \\
H_{1} \text { : Data have not a normal distribution } & \text { sig. }<0.05
\end{array}
$$

\section{Table 1}

One-sample Kolmogorove-Smirnov test for surveying the normal data

\begin{tabular}{llccccc}
\hline & & $\begin{array}{c}\text { Way of payment of } \\
\text { wage and salary }\end{array}$ & $\begin{array}{c}\text { Base of } \\
\text { payment }\end{array}$ & $\begin{array}{c}\text { Payment } \\
\text { index }\end{array}$ & $\begin{array}{c}\text { Equality of } \\
\text { payment }\end{array}$ & $\begin{array}{c}\text { Running } \\
\text { ability }\end{array}$ \\
\hline \multirow{2}{*}{ Normal parameters } & Mean & 97 & 97 & 97 & 97 & 97 \\
& Std. deviation & .56595 & .46794 & .53194 & .43835 & .43244 \\
\hline \multirow{2}{*}{$\begin{array}{l}\text { Most extreme } \\
\text { differences }\end{array}$} & Absolute & .152 & .130 & .104 & .137 & .110 \\
& Positive & .071 & .061 & .104 & .107 & .110 \\
& Negative & -.152 & -.130 & -.086 & -.137 & -.076 \\
\hline Kolmogorov-Smirnov $Z$ & 1.367 & 1.276 & 1.021 & 1.353 & 1.082 \\
\hline Asymp. sig. (2-tailed) & .053 & .077 & .248 & .051 & .192 \\
\hline
\end{tabular}

\subsection{Survey of the first subsidiary question of the research}

What is the way of payment in the wage and salary system in the given organization? This question is defined as the statistic hypothesis given below.

$$
\begin{cases}H_{0}: \mu \leq 3 & \text { sig. } \geq 0.05 \\ H_{1}: \mu>3 & \text { sig. }<0.05\end{cases}
$$


$H_{0}$ : The way of paying in the existing payment system with a high probability is not acceptable.

$H_{1}$ : The way of paying in the existing payment system with a high probability is acceptable.

As shown in Table 2 with regards to $t=-6.294<0$ and the observed significant level that is less than 0.05 , thus $H_{0}$ cannot be null. In other words, by considering the obtained results, the pay method in the studied organization is not accepted.

\section{Table 2}

Results of the $t$-test from the first subsidiary question of the research

Test value $=3$

\begin{tabular}{ccccc}
\cline { 2 - 5 } & $t$ & d.f. & Sig. (2-tailed) & Mean difference \\
\hline Payment method in wage & -6.294 & 96 & .000 & -.36168 \\
\hline
\end{tabular}

\subsection{Survey of the second subsidiary question of the research}

What is the base of payment of the existing payment system? This question is defined as the statistic hypothesis given below:

$$
\begin{cases}H_{0}: \mu \leq 3 & \text { sig. } \geq 0.05 \\ H_{1}: \mu>3 & \text { sig. }<0.05\end{cases}
$$

$H_{0}$ : The base of payment in the existing payment system with a high probability is not acceptable.

$H_{1}$ : The base of payment in the existing payment system with a high probability is acceptable.

As shown in Table 3 with regards to $t=-5.400<0$ and the observed significant level that is less than 0.05 , thus $H_{0}$ cannot be null. In other words, by considering the obtained results, the base of payment in the studied organization is not accepted.

Table 3

Results of $t$-test from the second subsidiary question of the research

\begin{tabular}{lcccc}
\hline & \multicolumn{4}{c}{ Test value $=3$} \\
\cline { 2 - 5 } & $t$ & d.f. & Sig. (2-tailed) & Mean difference \\
\hline Base of payment & -5.400 & 96 & .000 & -.23711 \\
\hline
\end{tabular}

\subsection{Survey of the third subsidiary question of the research}

What is the payment index of the existing payment system? This question is defined as the statistic hypothesis given below:

$$
\begin{cases}H_{0}: \mu \leq 3 & \text { sig. } \geq 0.05 \\ H_{1}: \mu>3 & \text { sig. }<0.05\end{cases}
$$

$H_{0}$ : The payment index of the existing payment system with a high probability is not acceptable.

$H_{1}$ : The payment index of the existing payment system with a high probability is acceptable.

As shown in Table 4 with regards to $t=-10.148<0$ and the observed significant level is less than 0.05 , thus, $H_{0}$ cannot be null. In other words, by considering the obtained results, the payment index in the studied organization is not accepted. 
Table 4

Results of $t$-test from a third subsidiary question of the research

\begin{tabular}{lcccc}
\hline & \multicolumn{4}{c}{ Test value $=3$} \\
\cline { 2 - 5 } & $t$ & d.f. & Sig. (2-tailed) & Mean difference \\
\hline payment index & -10.148 & 96 & .000 & -.54811 \\
\hline
\end{tabular}

\subsection{Survey of the forth subsidiary question of the research}

What is the equality of payment in the existing payment system of the organization? This question is defined as the statistic hypothesis given below.

$$
\begin{cases}H_{0}: \mu \leq 3 & \operatorname{sig} \geq 0.05 \\ H_{1}: \mu>3 & \operatorname{sig}<0.05\end{cases}
$$

$H_{0}$ : The equality of payment in the existing payment system with a high probability is not acceptable.

$H_{1}$ : The equality of payment in the existing payment system with a high probability is acceptable.

As shown in Table 5 with regards to $t=-3.872<0$ and the observed significant level is less than 0.05 , thus, $H_{0}$ cannot be null. In other words, by considering the obtained results, the equality of payment in the studied organization is not accepted.

\section{Table 5}

Results of $t$-test from the forth subsidiary question of the research

\begin{tabular}{lcccc}
\hline & \multicolumn{4}{c}{ Test value $=3$} \\
\cline { 2 - 5 } & $t$ & d.f. & Sig. (2-tailed) & Mean difference \\
\hline Equality of payment & -3.872 & 96 & .000 & -.17231 \\
\hline
\end{tabular}

\subsection{Survey of the fifth subsidiary question of the research}

What is the running ability of existing present system in the organization? This question is defined as the statistic hypothesis given below.

$$
\begin{cases}H_{0}: \mu \leq 3 & \text { sig } \geq 0.05 \\ H_{1}: \mu>3 & \text { sig }<0.05\end{cases}
$$

$H_{0}$ : The running ability of the existing payment system with a high probability is not acceptable.

$H_{1}$ : The running ability of the existing payment system with a high probability is acceptable.

As shown in Table 3 with regards to $t=-5.400<0$ and the observed significant level that is less than 0.05 , thus $H_{0}$ cannot be null. In other words, by considering the obtained results, the running ability in the studied organization is not accepted.

\section{Table 6}

Results of $t$-test from the fifth subsidiary question of the research

\begin{tabular}{lcccc}
\hline & \multicolumn{4}{c}{ Test value $=3$} \\
\cline { 2 - 5 } & $t$ & d.f. & Sig. (2-tailed) & Mean difference \\
\hline Running ability & -5.400 & 96 & .000 & -.23711 \\
\hline
\end{tabular}




\subsection{Survey of the general question of the research}

What is the situation of the existing payment system? This question is defined as the statistic hypothesis given below.

$$
\begin{cases}H_{0}: \mu \leq 3 & \text { sig. } \geq 0.05 \\ H_{1}: \mu>3 & \text { sig. }<0.05\end{cases}
$$

$H_{0}$ : The situation of the existing payment system with a high probability is not acceptable.

$H_{1}$ : The situation of the existing payment system with a high probability is acceptable.

As shown in Table 3 with regards to $t=-7.080<0$ and the observed significant level that is less than 0.05 , thus $H_{0}$ cannot be null. In other words, by considering the obtained results, the situation in the studied organization is not accepted.

Table 7

Results of $t$-test from the general question of the research

\begin{tabular}{ccccc}
\hline & \multicolumn{5}{c}{ Test value $=3$} \\
\cline { 2 - 5 } & $t$ & d.f. & Sig. (2-tailed) & Mean difference \\
\hline Payment system & -7.080 & 96 & .000 & -.26753 \\
\hline
\end{tabular}

In summary based on the data analysis, the following results related to each subsidiary question are given below.

Concerning the first subsidiary question (i.e., what is the way of payment in the wage and salary system in the considered organization?), we obtain $t=-6.294<0$. Therefore, we cannot reject $H_{0}$ with the significance level of $95 \%$. It means that the method of the related payment studied in this organization is not confirmed. In other words, we can conclude that in the respondent's point of view, this method is not effective and successful for employees, improvement of performance, having endurance and encouragement of employees, accomplishment strategies and organizational goals, changing employee's behavior towards ideal, ones supplying material necessities of employee, making good competition environment and balance between individuals and groups performance.

Concerning the second subsidiary question (i.e., what is the payment base in the existing payment system?), we obtain $t=-5.400<0$ and we cannot reject $H_{0}$ with the significance level of $95 \%$. It means that the payment basis studied in this organization is not confirmed. In other words, we can say that this research does not considerably pay attention to scientific and specialized competency of employee, competency of employee, degree of cooperation and role of employee in accomplishment of organizational goals; whereas, it pays attention to military service backgrounds and job experience of employee and changes of the life expense more and more.

Concerning the third subsidiary question (i.e., what is the payment index in the existing payment system?), we obtain $t=-10.148<0$ and we cannot reject $H_{0}$ with the significance level of $95 \%$. It means that the payment index studied in this organization is not confirmed. In other words, we can say that in the respondents' point of view, the payment index does not pay attention to standards and performance properties of employees, quantity and quality of people's job as well as quantitative and qualitative indexes of productive; whereas, it pays attention to job properties of employees more and more.

Concerning the forth subsidiary question (i.e., what is the equality of payment in the existing payment system?), we obtain $t=-3.872<0$ and we cannot reject $H_{0}$ with the significance level of $95 \%$. It means 
that the payment of wage and salary studied in this organization is not fair. In other words, we can say that this research in the payment system does not considerably pay attention to real value of people's job, received proportion employees with effort on their skills. In addition, there is much difference between payment levels of the studied organization with the similar organizations.

Concerning the fifth subsidiary question (i.e., what is the running ability of the existing payment system in the organization?), we obtain $t=-5.400<0$ and we cannot reject $H_{0}$ with the significance level of $95 \%$. It means that the running ability studied in this organization is not fair. In other words, we can say that in respondents' point of view, the existing payment system considerably pays attention to capability of understanding and transparency of values, increasing compatible ability of the organization in attraction of the skillful forces, possibility of updating to future needs and environmental changes for payment, related payment system with other subsystems of human resources. Whereas, this system pays attention more to limitations of the organization budget based on wage and salary payment.

In general, in the analysis of the collected data, the result of the main question (i.e., what is the situation of the existing payment system?), we obtain $t=-7.080<0$ and we cannot reject $H_{0}$ with the significance level of $95 \%$. In other words, by the obtained result, the situation of the payment system in the ideal studied organization is not evaluated the general conduction. It seems that the organization should review the payment of salary, wage and reward human resources under a longterm horizon.

\section{Discussion and conclusion}

In the survey of theoretic principles and past researches, we concluded that salary was as one of the compensation system sets in an organization service that can maintain or make dissatisfaction of the employees. However, these rewards should be distributed in the organization in such a way that the concept of compensation services should be maintained. Because if a relationship between the employee's services and organization rewards were not described or its distribution were not fair, it would make dissatisfaction in the organization. As a result, the employee would leave the organization and be attracted in a competitor organization or he/she would stay in the organization with dissatisfaction. In this case, the results of this problem are low morale, absence, obstruction and other similar factors.

By considering the obtained results, some future research areas are proposed in order to improve the existing situation of the payment. It was concluded that the method of wage and salary payment is in the ideal condition; however, authorities should improve possibilities in this domain with boosting motivational power of plan, with removing adventure in distribution system, making safe involvement in distribution of reward, using from group encouragement.

The indices of the wage and salary payment in the studied organization do not show the ideal situation; thus, it is necessary to review the indices distribution of rewards according to the qualitative and quantitative values of performance, and to emphasis on productivity as the main purpose of this plan. The equality sense in the payment system for employees is in minimum level. Therefore, it offers that management should make a logic relation between the attempted skill of employees and amount of the received wage and consider the level of the payment system at the similar organization (i.e., other governmental and non-governmental organizations). The performance capability of the payment system is doubted in the organization; thus, the system needs the required flexibility along with environmental changes and increases a compatible power of the organization in a competitive condition. In addition, this system should pay attention to the relation between payment and assessment of performance. 


\section{References}

Brian K. \& Salamin, A. (2001). Strategic reward systems: A contingency model of pay system design. Strategic Management Journal, 22(8), 777-792.

Brian, C., Carter, M.E. \& Hillegeist, S. (2010). The incentives of compensation consultants and CEO pay. Journal of Accounting and Economics, 49(3), 263-280.

Burke, L.A. \& Hsieh, C. (2005). Professional practice optimizing fixed and variable compensation costs for employee productivity. International Journal of Productivity and performance management, 55(2), 155-162.

Cardon, M.S. \& Stevens, C.E. (2004). Managing human resources in small organizations: What do we know?. Human Resource Management Review, 14(3), 295-323.

Deci E. L. (1972). The effects of contingent and Non contingent Rewards and controls on intrinsic motivation. Organizational Behavior and Human Performance, 8(2), 217-229.

Dohmen Thomas J. (2004). Performance, seniority and wages: Formal salary systems and individual earnings profiles. Labour Economics, 11(6), 741-763.

Eriksson, T., \& Lausten, M. (2000). Managerial pay and firm performance -- Danish evidence. Scandinavian Journal of Management, 16(3), 269-286.

Harwitz, F.M, Heng. T. \& Quazi, H.A.. (2003). Finders, keepers? attracting, motivating and retaining knowledge worker, Human Resource Management journal, 13(4), 23-44.

Heywood, J.S. \& Wei, X. (2006). Performance Pay and Job Satisfaction. Journal of Industrial Relations, 48, 523-540.

Issac, J.E. (2001). Performance-related pay: The importance of fairness, Journal of Industrial Relations, 43(2), 111-123.

Jensen, M.C. \& Murphy, K.J., (1990). Performance pays and top management incentives. Journal of Political Economy, 98(2), 225-264.

Koh, W.L. and Neo, A. (2000). An experimental analysis of the impact of pay for performance on employee satisfaction. Research and Practice in Human Resource Management, 8(2), 29-47.

Leetel, L. (2000). Wage equity and employee motivation in nonprofit and profit organizations. Journal of Economic Behavior and Organization, 43(4), 423-446.

Miceli M.P. \& Heneman, R.L. (2000). Contextual determinants of variable pay plan design: A proposed research framework. Human Resource management Review, 10(3), 289-305.

Mishra Chandra, S., McConaughy, D.L. \& Gobelia, D.H., (2000). Effectiveness of CEO payforperformance. Review of Financial Economics, 9, 1-13.

Rau, B.L. \& Feinauer, D. (2006). The role of internal agents in starting salary negotiations. Human Resource Management Review, 16(1), 47-66.

Rayton Bruce A. (2003). Firm performance and compensation structure: performance elasticity of average employee compensation. Journal of Corporate Finance, 9, 333-352.

Parent, D. (2004). Incentives? The effect of profit Sharing plans offered by previous employers on current wages. Economics Letters, 83(1), 37-42.

Piekkola, H. (2005). Performance-related pay and firm performance in Finland. International Journal of Manpower, 26(7/8), 619-635.

Schultz T. P. (2003). Wage rentals for reproducible human capital: Evidence from Ghana and the Ivory Coast. Economics and Human Biologr, 1(3), 331-366.

Singer, M, Donoso, C. \& Rodríguez-Sickert, C. (2008). A static model of cooperation for groupbased incentive plans. International Journal of Production Economics, 115(2), 492-501. 